\title{
Hybrid solar power plant with thermochemical energy storage: a multi-objective operational optimisation
}

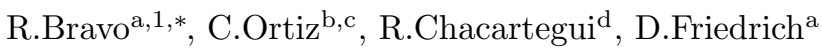 \\ ${ }^{a}$ School of Engineering, Institute for Energy Systems, The University of Edinburgh, UK \\ ${ }^{b}$ Facultad de Física, Universidad de Sevilla, Avenida Reina Mercedes s/n, 41012, Sevilla, Spain \\ ${ }^{c}$ Departamento de Ingeniería, Universidad Loyola Andalucía, Av. de las Universidades s/n, Dos Hermanas, 41704, Sevilla, Spain \\ ${ }^{d}$ Departamento de Ingeniería Energética, Universidad de Sevilla, Camino de los Descubrimientos s/n, 41092, Sevilla, Spain
}

\begin{abstract}
Energy storage is key to decarbonising the energy sector by reducing intermittency and increasing the integration of renewable energy. Thermochemical energy storage (TCES) integrated with concentrated solar and photovoltaic power plants, has the potential to provide dispatchable and competitive energy. Here we develop a multi-objective optimisation framework to find the best operational strategy of a hybrid solar power plant with a TCES system. The model uses a typical meteorological year to optimise one-year hourly operation. The results demonstrate that the integration of a calcium-looping process as TCES in a concentrating solar power plant provides dispatchability and, when hybridised with photovoltaic, enhances its competitiveness with current electricity prices. The low mismatch between supply and demand, even when a fixed commitment is required throughout the year, together with a high overall efficiency, indicates that the integration of calcium-looping in hybrid solar power plants is an opportunity to increase the penetration of solar energy in the power sector. Through the optimisation framework presented, a seasonal energy storage analysis can be developed, although a second optimisation stage is required to improve the sizing of the main components of the system in order to further reduce the energy costs.
\end{abstract}

Keywords: Calcium-looping, Thermochemical energy storage, Hybrid energy systems, Concentrating solar power, Photovoltaic systems, Multi-objective optimisation

\section{Introduction}

Renewable energies are key to enhance the sustainable development and decarbonisation of the power sector, and its agile implementation is required to reduce the negative effects of global warming [1]. Renewable power plants (other than hydropower) have low maintenance and operational costs [2], their carbon emissions are substantially lower compared to fossil fuel power stations [3] and their development is key to energy independence. However, these are not dispatchable (i.e. renewable power plants can dispatch energy just when the resource is available). Some renewable power plants are very competitive, where in some locations, bids for recent auctions have reached prices even below $20 U S D M W h^{-1}$ (mainly based on wind and solar technologies) [4].

The continuous growth in the penetration of renewable energy technologies in the power sector and the natural variability of the resource (e.g. solar, wind) adds large fluctuations in generation and large mismatches with power

\footnotetext{
${ }^{*}$ Corresponding author

Email address: r.bravo@ed.ac.uk (R.Bravo)

${ }^{1}$ The author is supported by a PhD student scholarship from BECAS CHILE, CONICYT.
}

demand [5]. To reduce variability and increase dispatchability of renewable power plants, the integration of energy storage allows to have control in the power dispatch [6]. Therefore, to increase the penetration of solar technologies in the power sector, the integration of energy storage is essential. On the one hand, in the case of photovoltaic systems, despite the fact that the rate of projects under development is very high, the integration of electric batteries as energy storage is not economically feasible [7], but it could be competitive in the long term if the current high price of large scale electric batteries is reduced considerably [8]. On the other hand, concentrating solar power technologies integrated with energy storage are key systems that could provide clean and dispatchable energy at competitive costs [9], and even more competitive when flexibility is given by integrating a small fossil backup unit, allowing some carbon emissions but increasing its dispatchability and capacity factor [10].

Different energy storage technologies have been proposed in concentrating solar power plants, based on three different concepts: sensible, latent and thermochemical energy storage. Sensible thermal energy storage is a mature technology used in concentrating solar power plants, which works with a temperature difference of a substance, for example, water or molten salts [11]. Latent thermal 
energy storage uses the heat that can be stored or released during the phase change of a material [12]. Finally, thermochemical energy storage uses the heat of reaction of a reversible chemical reaction that absorbs and rejects energy depending on the operation [13]. One of the promising thermochemical energy storage technologies that can be integrated into concentrating solar power plants is the calcination-carbonation process of calcium carbonate [14], according to the following reaction that involves calcium carbonate $\left(\mathrm{CaCO}_{3}\right)$, calcium oxide $(\mathrm{CaO})$ and carbon dioxide $\left(\mathrm{CO}_{2}\right)$ :

$$
\begin{aligned}
& \mathrm{CaCO}_{3(s)} \rightleftarrows \mathrm{CaO}_{(s)}+\mathrm{CO}_{2(g)} \\
& \text { with } \Delta \hat{H}_{r}^{\circ}=178 \mathrm{~kJ} \mathrm{~mol}^{-1}[15]
\end{aligned}
$$

The integration of this process, also known as calciumlooping $(\mathrm{CaL})$, as a energy storage system, has several benefits. For instance, because its high energy density, a relatively small storage volume has the potential to operate as long-term energy storage, and the precursor materials used in the process, such as limestone or dolomite, are an abundant, non-corrosive, non-toxic and cheap material [14]. Hence, the integration of CaL process as thermochemical energy storage (TCES) technology in concentrating solar power plants is a suitable sustainable alternative to provide dispatchable power.

Several studies exploit synergies between expensive but dispatchable power plants, such as concentrating solar power (CSP) with thermal energy storage, integrated with affordable but intermittent renewable technologies, e.g. photovoltaic (PV) [10], [16]. These studies, based on the application of optimisation techniques, focus on the development of operational strategies that minimises and/or maximises different key performance indicators as objective functions. Previous studies do not exploit the capacity of linear programming to optimise the annual performance of hybrid solar power plants with thermochemical energy storage systems, taking into account the daily and seasonal variability of the solar resource. In this context, [10] optimises the operation of a hybrid solar power plant integrated with thermal energy storage in the Atacama Desert, concluding that a multi-objective optimisation routine is crucial to estimate and analyse the trade-off between technical and financial performance.

In the present study, a multi-objective linear optimisation model that optimises the one-year hourly operation strategy of a hybrid solar power plant with thermochemical energy storage is developed and presented. The results of this multi-objective optimisation method is a Pareto frontier that represents the trade-off between two objectives, in this case the total net energy dispatched ( $G W h$ year $\left.{ }^{-1}\right)$ that influences the levelised cost of the electricity, and the mismatch between supply and demand, estimated here through the loss of power supply capacity $\left(G W h\right.$ year $\left.{ }^{-1}\right)$, that represents the dispatchability of the power plant under a given commitment.

\section{Abbreviations}

DNI: Direct normal irradiation

GTI: Global tilted irradiation

TMY: Typical meteorological year

CSP: Concentrating solar power

CaL: Calcium-looping process

TCES: Thermochemical energy storage

PV: Photovoltaic

LCOE: Levelised cost of electricity

LPS: Loss of power supply

SoC: State of Charge

\section{Nomenclature}

$i$ : subscript, period (hours)

$k$ : subscript, material

$\mathrm{DNI}_{i}$ : direct normal irradiation period i

$\mathrm{GTI}_{i}$ : global tilted irradiation period i

$A^{\mathrm{CSP}}$ : solar tower heliostats field area

$P^{\mathrm{ST}}$ : steam turbine capacity

$P^{\mathrm{MC}}$ : main $\mathrm{CO}_{2}$ compressor capacity

$P^{\mathrm{MT}}$ : main $\mathrm{CO}_{2}$ turbine capacity

$P^{\text {HPSC }}$ : high pressure $\mathrm{CO}_{2}$ compressor capacity

$P^{\mathrm{HPST}}$ : high pressure $\mathrm{CO}_{2}$ turbine capacity

$\mathrm{STO}^{\mathrm{CO}_{2}}$ : $\mathrm{CO}_{2}$ storage vessel capacity

$S T O^{\mathrm{CaO}}: \mathrm{CaO}$ storage tank capacity

STO $O^{\text {Solids }}$ : Solids storage tank capacity

$A^{\mathrm{PV}}$ : photovoltaic field area

$\eta^{\text {opt }}$ : optical efficiency solar field (DNI to receiver)

$\eta^{\text {receiver }}$ : thermal efficiency receiver

$P_{i}^{\text {net }}$ : net power period i

$E^{\text {net }}$ : net energy generated

$P_{i}^{\text {demand }}$ : power demand period i

$\mathrm{LPS}_{i}$ : loss of power supply period $\mathrm{i}$

$\hat{m}_{i}$ : molar flow rate $(\mathrm{kmol} / \mathrm{s})$

$\dot{m}_{i}$ : mass flow rate $(\mathrm{kg} / \mathrm{s})$

$\hat{h}$ : molar enthalpy $(k J / \mathrm{mol})$

$h$ : enthalpy $(\mathrm{kJ} / \mathrm{kg})$

$M W_{i}$ : molecular weight, component i

$\Delta \hat{h}_{f, i}^{0}:$ molar enthalpy of formation

$X$ : $C a O$ conversion

\section{Methodology and Framework description}

In this section, the modelling of a CaL thermochemical energy storage process, integrated in a hybrid solar power plant, is presented. Then, a multi-objective optimisation method to define the best one-year hourly operational strategy is described.

\subsection{Description}

Figure 1 represents the process involved in the generation of electricity through the use of a CaL process integrated in a CSP and hybridised with a PV system. The 
CSP-CaL scheme (and nomenclature) is taken from the base case proposed in [17]. Each stream is represented by a letter and a number, where the letter defines the type of substance (g: $\mathrm{CO}_{2}$; c: $\mathrm{CaO}$; s: solids $\mathrm{CaO}+\mathrm{CaCO}_{3}$ ), and the number indicates the correlative the position of the stream in the diagram. For the present study, a Python model has been developed to optimise the operation of a hybrid solar plant with CaL energy storage by mass and energy balances. This model uses real solar irradiation as input, and by linear programming, optimises the annual hourly operation of a defined power plant (CSP with $\mathrm{CaL}$ plus PV). Note that the current algorithm optimises the plant operation and not the components sizing; hence, the capacity of each component in this study is an input to the model. The following list summarised the capacities of the main components of the power plant:

- Solar Tower field area: $A^{\mathrm{CSP}}, \mathrm{m}^{2}$

- Steam Turbine capacity: $P^{\mathrm{ST}}, M W$

- Main $\mathrm{CO}_{2}$ Compressor capacity: $P^{\mathrm{MC}}, M W$

- Main $\mathrm{CO}_{2}$ Turbine capacity: $P^{\mathrm{MT}}, M W$

- High Pressure $\mathrm{CO}_{2}$ Compressor capacity: $P^{\mathrm{HPSC}}$, $M W$

- High Pressure $\mathrm{CO}_{2}$ Turbine capacity: $P^{\mathrm{HPST}}, \mathrm{MW}$

- $\mathrm{CO}_{2}$ Storage Vessel: $\mathrm{STO}^{\mathrm{CO}_{2}}, \mathrm{~m}^{3}$

- $\mathrm{CaO}$ Storage Tank: $S T O^{\mathrm{CaO}}, \mathrm{m}^{3}$

- Solids Storage Tank: STO $O^{\text {Solids }}, \mathrm{m}^{3}$

- Photovoltaic field area: $A^{\mathrm{PV}}, m^{2}$

In the model, the CSP is a solar tower technology that provides heat to carry out the endothermic reaction that splits $\mathrm{CaCO}_{3}$ into $\mathrm{CaO}$ and $\mathrm{CO}_{2}$ at $900^{\circ} \mathrm{C}$, according equation 1. The location where this reaction takes place is known as calciner and coincides with the solar receiver. Full calcination is assumed in the model [18]. CaO exiting the calciner is stored at atmospheric pressure and high temperature in an insulated tank. The second stream that exits the calciner, consisting of pure $\mathrm{CO}_{2}$ at $900^{\circ} \mathrm{C}$, first exchanges heat in a Heat Recovery Steam Generator (HRSG) to produce electricity. Next, the $\mathrm{CO}_{2}$ leaves the heat exchanger and cools to approximately $40^{\circ} \mathrm{C}$ to improve the efficiency of the compression process that is occurring afterwards. After the compressor, this stream (now with a pressure of approximately 3 bar) has two possibilities: (i) it can be used in the carbonator to produce the reversible exothermic reaction (carbonation) where it reacts with $\mathrm{CaO}$ from the $\mathrm{CaO}$ storage tank forming $\mathrm{CaCO}_{3}$ and releasing heat according to the previous reaction; (ii) or can be stored at high pressure in a 75 bar vessel, by using a multi-stage compressor. Then, when power needs to be dispatched, this high-pressure stream first drives a turbine to generate electricity and then mixes with the stream flowing from the power loop. This flow is heated in a regenerative system, which reaches around $654^{\circ} \mathrm{C}$ and is then sent to the carbonator to drive the exothermic reaction described above. The $\mathrm{CaO}$ conversion $(\mathrm{X})$ in the carbonator is highly dependent on the reactors conditions (pressure, temperature, $\% \mathrm{v} / \mathrm{v} \mathrm{CO}_{2}$ ) and the $\mathrm{CaO}$ precursor used [19]. In this work, a conservative value of $\mathrm{X}=0.15$ is assumed. The heat released from the reaction is taken by the $\mathrm{CO}_{2}$ that is present in excess in the carbonator. After that, this pure $\mathrm{CO}_{2}$ stream runs a gas turbine (main turbine) to produce electricity that is used to drive the main compressor and the surplus is dispatched to the network. The $\mathrm{CO}_{2}$ leaves the turbine at 1 bar and approximately $700^{\circ} \mathrm{C}$ and then it exchanges heat in the regenerative system to increase the temperature of the $\mathrm{CO}_{2}$ stream before entering the carbonator. Then, the $\mathrm{CO}_{2}$ flow described above is cooled to $40^{\circ} \mathrm{C}$ to be compressed in the main compressor, closing the cycle (see figure 1).

\subsection{Energy systems analysis}

The following section describes the mass and energy balances used in the model for the operation of the main processes of the power plant. The main components are: solar field (heliostats and receiver), reactors (carbonator and calciner), heat exchangers, coolers, compressors and turbines. Main properties for $\mathrm{CaCO}_{3}, \mathrm{CaO}$ and $\mathrm{CO}_{2}$ are summarised in table 1 . All the variables described below are non-negative real numbers unless otherwise stated.

\subsubsection{Solar field:}

In the solar field, each heliostat focuses the solar irradiation on the calciner that is located in the top of the solar tower (receiver). The total thermal power transferred and used in the receiver at each time step $\left(Q_{i}^{\text {calciner }}\right)$ is calculated according equation 2 .

$$
Q_{i}^{\text {Calciner }}=D N I_{i} \cdot \eta_{i}^{o p t} \cdot \eta^{\text {receiver }} \cdot A^{C S P}-Q_{i}^{\text {Curtailment }}
$$

Where $D N I_{i}$ is the direct normal irradiation, $A^{C S P}$ is the total area covered by the heliostats, $\eta_{i}^{o p t}$ is the optical efficiency of the solar field that varies every hour in the model and depends on the relative position between the sun, the heliostats and the tower (including losses related to blocking, soiling, reflectance, attenuation, interception and cosine effect [20]) and $\eta^{\text {receiver }}$ is the efficiency of the receiver, which is assumed in this work as 0.85 [20]. A sensitivity analysis on this value is carried out in section 4.1. The curtailment $\left(Q_{i}^{\text {curtailment }}\right)$ is the power that have to be curtailed when the power cycle is running at full capacity and the storage system is fully charged.

\subsubsection{Calciner:}

The endothermic calcination reaction occurs within the calciner, which in this case coincides with the receiver chamber located in the top of the tower. In this reaction, the stream $s 2$, which contains calcium carbonate and calcium oxide, is heated to $900^{\circ} \mathrm{C}$ when the endothermic reaction starts. Hence, because there is no accumulation of energy in the system, nor shaft work, all the heat from 


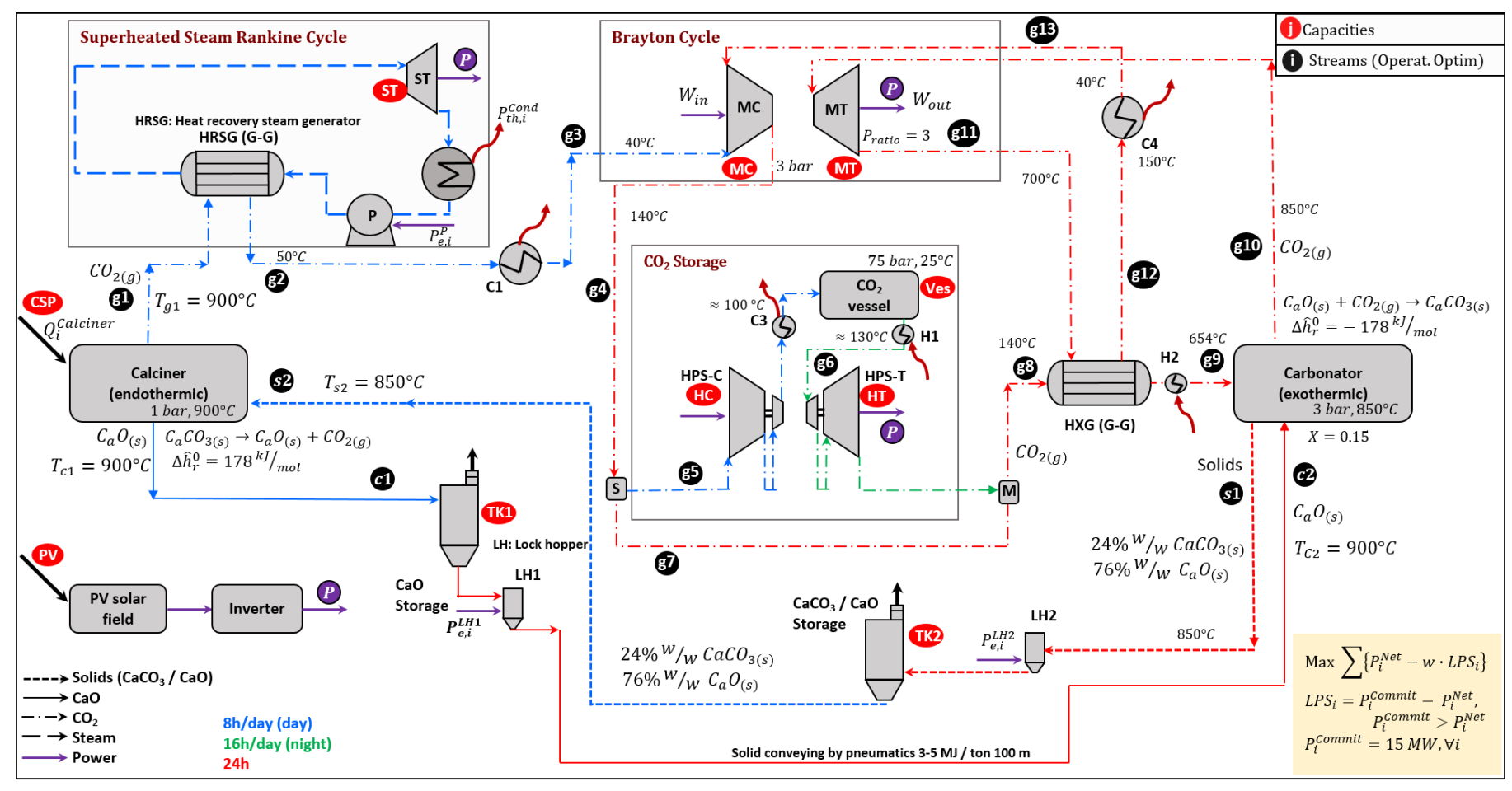

Figure 1: Mass and energy flow model of the calcium-looping system

the solar field is used to heat the stream $s 2$ and complete the reaction, according to:

$$
\begin{aligned}
Q_{i}^{\text {Calciner }} & =\Delta\left(\hat{m}_{k, i} \cdot \hat{h}_{k, i}\right)+\Delta \hat{h}_{r, i} \\
\text { with, } & \\
\Delta\left(\hat{m}_{k, i} \cdot \hat{h}_{k, i}\right) & =\hat{m}_{g 1, i} \cdot \hat{h}_{g 1, i}+\hat{m}_{c 1, i} \cdot \hat{h}_{c 1, i}-\hat{m}_{s 2, i} \cdot \hat{h}_{s 2, i} \\
\Delta \hat{h}_{r, i} & =\hat{m}_{s 2, i} \cdot \Delta \hat{H}_{r}^{\circ}
\end{aligned}
$$

In molar terms, the molar flow rate of $\mathrm{CO}_{2}$ (stream $g 1$ ) is equal to the molar flow rate of $\mathrm{CO}_{2}$ produced in the reaction. Finally, the $\mathrm{CaO}$ molar flow rate ( $\operatorname{stream~} c 1$ ) is equal to the molar flow rate of $\mathrm{CaO}$ in stream $s 2$ plus the molar flow rate of $\mathrm{CaO}$ produced in the reaction.

\subsubsection{Heat exchangers and coolers:}

In a heat exchanger, there is no energy accumulation, and if considered as adiabatic, the amount of heat transferred from the hot fluid (h) to the cold fluid (c) can be modelled by [22]:

$$
\begin{gathered}
\dot{m}_{h_{\text {in }, i}} \cdot h_{h_{\text {in }, i}}-\dot{m}_{h_{\text {out }}, i} \cdot h_{h_{\text {out }}, i}= \\
\dot{m}_{c_{\text {out }}, i} \cdot h_{c_{\text {out }}, i}-\dot{m}_{c_{\text {in }}, i} \cdot h_{c_{\text {in }}, i}
\end{gathered}
$$

Coolers are modelled similarly to heat exchangers (no energy accumulation, no shaft work, adiabatic), the difference here is that the working fluid cools while a refrigerant is heating (air in this case). The energy balance for coolers is described as:

$$
\dot{m}_{r, i} \cdot c_{p_{r}} \cdot \Delta T_{r, i}=\dot{m}_{h_{i n}, i} \cdot\left(h_{h_{\text {out }}, i}-h_{h_{i n}, i}\right)
$$

Where $c_{p_{r}}$ is the specific heat capacity of the refrigerant $\left(c_{p, \text { air }}\left(23^{\circ} \mathrm{C}, 41 \%\right.\right.$ rel. humidity $\left.)=1.012 \mathrm{~kJ} / \mathrm{kg} \cdot \mathrm{K}[15]\right)$

\subsubsection{Superheated steam Rankine cycle:}

In order to simplify the model, the turbine power output (ST) of the Rankine cycle is simulated as a linear relation with the heat absorbed in the heat recovery steam generator (HRSG) according to:

$$
P_{i}^{S T}=Q_{i}^{H R S G} \cdot \eta^{S S R C}
$$

where $\eta^{S S R C}$ is the global efficiency from thermal to electrical power. Based on models and results analysed by using the commercial software ASPEN PLUS, an efficiency $\eta^{S S R C}=0.268$ will be considered in this study.

\subsubsection{Compressors and turbines:}

The following relations are used to estimate the total work in turbines and compressors according to [23]:

$$
\begin{aligned}
& \Delta\left(\dot{m}_{i} h_{\text {turb }, i}\right)=\dot{m}_{i} \frac{\gamma_{i}}{\gamma_{i}-1} \frac{P_{\text {in }, i}}{\rho_{\text {in }, i}}\left\{1-\left(\frac{P_{\text {out }, i}}{P_{\text {in }, i}}\right)^{\frac{\gamma_{i}-1}{\gamma_{i}}}\right\} \eta_{s} \\
& \Delta\left(\dot{m}_{i} h_{\text {comp }}\right)=\dot{m}_{i} \frac{\gamma_{i}}{\gamma_{i}-1} \frac{P_{\text {in }, i}}{\rho_{\text {in }, i}}\left\{\left(\frac{P_{\text {out }, i}}{P_{\text {in }, i}}\right)^{\frac{\gamma_{i}-1}{\gamma_{i}}}-1\right\} \eta_{s}
\end{aligned}
$$


Table 1: Properties of main components

\begin{tabular}{l|c|c|c}
\hline & $\Delta \hat{h}_{f}^{0}(\mathrm{~kJ} / \mathrm{mol})[15]$ & $C p(\mathrm{cal} / \mathrm{mol} \cdot \mathrm{K})[21]$ & $M W(\mathrm{~kg} / \mathrm{kmol})[21]$ \\
\hline $\mathrm{CaCO}_{3}$ & -1207 & $19.68+0.01189 \cdot \mathrm{T}-307600 \cdot T^{-2}$ & 100.09 \\
$\mathrm{CaO}$ & -635 & $10.00+0.00484 \cdot \mathrm{T}-108000 \cdot T^{-2}$ & 56.08 \\
$\mathrm{CO}_{2}$ & -394 & $10.34+0.00274 \cdot \mathrm{T}-195500 \cdot T^{-2}$ & 44.01 \\
\hline
\end{tabular}

where $\gamma$ is the heat capacity ratio, used here as the isentropic expansion factor, and $\eta_{s}$ is the isentropic efficiency of the turbine or compressor.

\subsubsection{Carbonator:}

In the carbonator, the reverse reaction of the calciner occurs. In this reactor, pure $\mathrm{CaO}$ from the $\mathrm{CaO}$ storage tank is combined with $\mathrm{CO}_{2}$ from the $\mathrm{CO}_{2}$ storage cycle to produce $\mathrm{CaCO}_{3}$ and heat (with a conversion of $15 \%$ ). After the carbonator, while the resulting solid stream $\mathrm{CaO}+$ $\left.\mathrm{CaCO}_{3}\right)$ is stored in the solid storage tank, the $\mathrm{CO}_{2}$ stream (presented here in excess to absorb the heat released in the reaction) is first conducted to a turbine to produce electricity, then to a heat exchanger to use part of the heat available in the regenerative system, finally to a cooler and compressor to close the cycle.

\subsubsection{Storage tanks:}

The three storage components ( $\mathrm{CaO}$ and solids storage tanks, and the $\mathrm{CO}_{2}$ storage vessel) are modelled by mass balances. Where the density under storage conditions considers internal porosity and particle packing density of the material, as described in [17]. Here the state of charge $\left(S o C_{i}\right.$ in $\left.m^{3}\right)$ is defined as the volume of material that is present in the tank in period $i$, which is equal to the state of charge of the previous period plus the input minus the output flows during the current period (in $m^{3}$ ), according to the following expressions:

$S o C_{i}\left(m^{3}\right)= \begin{cases}S o C_{i=0}(\%) \cdot S T O^{\text {capacity }}\left(m^{3}\right), & \text { if } i=0 \\ S o C_{i-1}+\left(\dot{m}_{\text {in }}-\dot{m}_{\text {out }}\right) \cdot \Delta t \cdot \frac{1}{\rho_{i}}, & i \geq 1\end{cases}$

In our model, the state of charge (in percentage) for each tank at the start of the operation $(\mathrm{i}=0)$ is defined as:

$$
S_{0} C_{i=0}= \begin{cases}100 \% & \mathrm{CaO} \text { tank } \\ 0 \% & \text { Solids }\left(\mathrm{CaO}+\mathrm{CaCO}_{3}\right) \text { tank } \\ 100 \% & \mathrm{CO}_{2} \text { vessel }\end{cases}
$$

This means that during the operation of the first hours, the storage tanks of the thermochemical energy storage system are fully charge, which allows the plant to dispatch energy even without solar irradiation. This is just a criterion for the simulations, which has insignificant influence in the yearly results. In the operational optimisation routine, to calculate the actual net energy dispatched, it is necessary to estimate the difference between the available energy in the initial and final periods of the annual operation. To calculate this difference, an averagge energy density factor $(\xi)$ is calculated as the rate between net power dispatched and $\mathrm{CaO}$ mass flow rate that feeds the carbonator:

$$
\xi_{i}\left(\frac{M W h}{\text { ton }_{C a O}}\right)=\frac{P_{i}^{\text {net }}(M W)}{\dot{m}_{c 2}\left(\frac{k g_{C a O}}{s}\right) \cdot 3600\left(\frac{s}{h}\right) \cdot \frac{1}{1000}\left(\frac{\text { ton }}{k g}\right)}
$$

The results of the model were analysed along the year to estimate this rate and a specific power production value of $\xi_{i} \approx 0.053 \mathrm{MWh}_{\text {ton }_{\mathrm{CaO}}}^{-1}$ was calculated.

\subsubsection{Photovoltaic power plant:}

Finally, the photovoltaic power plant converts the solar irradiation (in this case, the total irradiance received on a plane with fixed tilt) that reaches each solar module into electric power by the photovoltaic effect. In the simplified model shows in figure 1 , the power flows to the inverter and then is dispatched to the grid. According the model described in [24], the total efficiency of the PV plant, from the solar irradiation to the electric power, considers the efficiency of panels and inverters, in addition with the losses related with module mismatch, connections and wiring.

\subsection{Key performance indicators}

In order to compare the operational strategy of different configurations based on measurable results, the following are key indicators for technical and financial performance used in this study:

- $E^{n e t}$ is the total net electric energy dispatched by the power plant in one year of operation.

- LPSC is the total loss of power supply capacity during one year of operation, and LPSP is the loss of power supply probability according to:

$$
\begin{aligned}
& L P S C=\sum L P S_{i} \\
& L P S P=\frac{L P S C}{P_{i}^{\text {Commitment }} \cdot 8760}
\end{aligned}
$$

- $E^{\text {Commitment }}$ is the electricity dispatched to fulfil the commitment .

- $E^{\text {Excess }}$ is the electricity dispatched when the net energy exceeds the commitment (in this model there is no restriction for the maximum power dispatched).

- $E^{\text {Curtailed }}$ is the amount of energy available in the heliostat solar field that has to be curtailed when the power plant is running at full capacity and the storage tanks are fully charged. 
- $\Delta E_{f-i}$ is the energy difference between the last hour and the first hour of operation. This difference is used to calculate the net electricity dispatched during one year of operation.

- $\bar{P}^{\text {Net }}$ is the average power dispatched in one year, according to:

$$
\bar{P}^{N e t}=\frac{E^{N e t}}{8760}
$$

- $P^{M a x}$ is the maximum power dispatched during at least one hour, over one year of operation.

- $C F^{C S P}$ is the capacity factor referred to the $\mathrm{CO}_{2}$ Brayton cycle [25].

Two estimations for efficiencies will be calculated:

- $\eta^{C S P, R e c}$ is the efficiency of the solar tower power plant considering the energy available and used in the calciner:

$$
\eta^{C S P, R e c}=\frac{\sum E_{i}^{N e t *, C S P}}{\sum Q_{i}^{\text {Calciner }}}
$$

- $\eta^{C S P, D N I}$ is the overall efficiency of the solar power plant considering the solar energy available in the solar field:

$$
\eta^{C S P, D N I}=\frac{\sum E_{i}^{n e t *, C S P}}{\sum D N I_{i} \cdot A^{C S P}}
$$

- Levelised cost of the energy: representing the present value (considering an annual interest rate of $r=7 \%$ ) of the total life cycle costs (TLCC) involved in the generation of each unit of energy during the lifetime of the power plant ( $N=25$ years).

$$
L C O E=\frac{T L C C}{E^{N e t *}} \cdot \frac{r}{1-(1+r)^{-N}}[26]
$$

\subsection{Operational optimisation by linear program- ming}

In order to simplify the optimisation of the power plant, all equations and relationships are linearised. Then, to avoid bi-linear terms, because the operation of a subsystem depends on the input and output streams, and the energy balances depend on the temperature and mass flow, for the next calculations, all temperatures are considered fixed and defined according to [17]. In the power plant, this may be possible through the definition and control of temperatures, however, a future study would increase the complexity of the model (by using non-linear terms) to further improve the operational strategy. Furthermore, the operational optimisation routine optimises the mass flow rate of some streams and calculate those that are dependent (because there are directly relationships between some streams) in order to optimise the operation.

Optimisation objectives can be defined according to user preferences, and these can be easily changed in the model. In this study, for a fixed power plant, the objectives of the operational optimisation are defined by:

- Maximisation of the net energy supplied during one year of operation (typical year), where the hourly net power dispatched is defined by:

$$
P_{i}^{N e t}=P_{i}^{\text {Generated }}-P_{i}^{\text {Own consumption }}
$$

- Minimisation of the loss of power supply (LPS), which estimates the mismatch between the energy supplied and the commitment, i.e. the net power to be dispatched by the power plant, according to the following equation:

$$
L P S_{i}= \begin{cases}P_{i}^{\text {Commitment }}-P_{i}^{N e t} & , P_{i}^{\text {Commitment }}>P_{i}^{N e t} \\ 0 & , \text { otherwise }\end{cases}
$$

\subsection{Scalarisation method}

In order to handle both objectives, and according to the results presented in [24], here a linear scalarisation method is implemented. The model developed in [24], which optimises the annual operation of a hybrid solar power plant with energy storage, found that the linear scalarisation method works faster than the epsilon $(\epsilon)$ constrain method, obtaining the same Pareto frontier. The only precaution is to choose a suitable scaling factor $(\omega)$ to scale the second objective (section 3.3 presents the analysis to define the value of $\omega$ for the case study described below). Therefore, the function that describes the multi-objective optimisation problem in the present study is:

$$
\text { maximize } \sum_{i=1}^{I}\left\{P_{i}^{N e t} \cdot \Delta t_{i}-w \cdot L P S_{i} \cdot \Delta t_{i}\right\}
$$

\subsection{Computer system and tools}

All optimisations presented in this study were performed using the following resources:

- PC: Intel Core i7-6700 CPU @ $3.4 \mathrm{GHz}, 16 \mathrm{~GB}$ RAM.

- Operating system: 64-bits Windows 10 Education.

- Programming language: Python 3.5.3 [27]

- Optimisation package: Pyomo 5.6.1 [28], [29]

- Solver: Gurobi 8.1.1 [30]

\section{Case Study}

To evaluate the model and compare the results with published data, the power plant under analysis will be located in Seville, Spain. Here public data available for Seville is used $\left(\approx \mathrm{N} 37.4^{\circ} \mathrm{W} 6.2^{\circ}\right.$, elevation $\left.72 \mathrm{~m}\right)$, in the "Photovoltaic Geographical information system" (PVGIS project) of the European Commission Joint Research Centre [31]. 


\subsection{Input data}

To run the model, the following hourly annual input data is required:

- Direct normal irradiation (DNI)

- Optical efficiency solar field $\left(\eta^{o p t}\right)$

- Global tilted irradiation (GTI)

In the present study, the typical meteorological year (TMY) is used as a representative year. Then, the direct normal irradiation is used to model a solar tower plant in SAM 2019 [20] to estimate the hourly optical efficiency of the heliostat field of the solar tower system. While values of hourly optical efficiency during summer days are from 0.42 to 0.6 , winter day values are between 0.3 to 0.55 , and the annual average value $\left(\bar{\eta}^{\text {opt }}\right)$ is around 0.53 .

According to the previous equations and relations, the model also needs a series of technical and financial parameters. Among the technical parameters necessary to run the model are: efficiencies of each component from [20], thermodynamic properties of the elements from table 1 , and operational temperatures and pressures of each subsystem from [32].

The necessary financial parameters are the investment costs (IC) and operational and maintenance costs (O\&MC) of the solar tower, the CaL system and the photovoltaic system. The capital cost of the heliostat field, the solar tower and the photovoltaic system were obtained by modelling both a solar tower power plant and a photovoltaic system in SAM [20]. Then, the estimate of the total land area and cost (using a value of $25000 U S D / h a$ ) was used from these simulations. Capital costs for the calciner (here the investment cost was increased by $10 \%$ to include the connections necessaries to install it in the solar tower receiver), carbonator, compressors, turbines, and other major components for the CaL system are summarised in table 2. For the calciner and carbonator, equations 2 and 21 are used to estimate the thermal power in order to calculate the scaling parameter applied in the equation for investment cost:

$$
Q^{\text {Carbonator }}=Q^{\text {Calciner }} \cdot \eta^{\text {overall,th }}
$$

where $\eta^{\text {opt }} \approx 0.53, \eta^{\text {receiver }}=0.85, D N I_{\text {design }}=0.95 \mathrm{~kW} / \mathrm{m}^{2}$, $Q^{\text {curtailment }}=0$, and $\eta^{\text {overall,th }}=0.9$.

Finally, a contingency of $7 \%$ and an EPC (engineering, procurement and construction) cost of $13 \%$ were considered [20]. In addition, to include all other components and auxiliary systems, a balance of plant of $10 \%$ was used.

The last necessary input data is the hourly power that the power plant have to dispatch: $P_{i}^{\text {demand }}$. This is used to calculate the loss of power supply $\left(\mathrm{LPS}_{i}\right)$ as a metric to estimate the reliability or dispatchability of the power plant under that commitment.

\subsection{Validation Aspen Plus ${ }^{T M}$}

In order to validate the model, different configurations (based on [17]) were evaluated using Aspen Plus ${ }^{T M}$ and optimised by our model written in Python. Table 3 compares three different cases, which shows the mass flow rate of different streams $\left(k g s^{-1}\right)$ and the energy generation and consumption in turbines, compressors, and heat exchangers $(M W)$. In the table, the three sections in the first row indicate: the thermal power available in the calciner $\left(M W_{t h}\right)$, solar multiple (SM) as described in [37] and $\mathrm{CaO}$ conversion in the carbonator $(\mathrm{X})$. As can be seen in the table, in most of the values, the difference between the values obtained through the Python and Aspen models is less than $1 \%$.

\subsection{Linear scalarisation method, definition of $\omega$}

In the present study, as shown in table 4, different optimisation routines with different $\omega$ were evaluated (according section 2.5). Table 4 shows that an $\omega=1$ is a suitable scaling factor. This can be explained because the units of both objectives are the same and both have the same order of magnitude in each operation time step. In addition, in the present model there are no penalties or cost for energy not served. In other cases, for instance, when the cost associated with unserved energy is greater than the cost of energy generation, a large scaling factor may be more appropriate.

\subsection{Solar Power Plant Design}

According figure 1, to optimise the annual operation of the power plant, the equipment sizes have to be known. This section presents a process to estimate the capacities of each main component using the equations and relationships described above. In a future study, this method will be improved by defining a second optimisation stage (similar to the design optimisation routine by genetic algorithms developed in [10]).

To establish a case study, it is necessary to define the capacities of the main components of the solar power plant. The process starts with the definition of the expected average power dispatched by the $\mathrm{CSP}+\mathrm{CaL}$ system. In this case, a capacity of $15 \mathrm{MW}$ is defined. Then, according to the estimated global efficiency value reported in [17] $\left(\eta_{C S P, R e c}=0.321\right)$, it is possible to estimate the average power needed in the calciner: $\bar{Q}^{\text {calc }} \approx 47 M W_{t h}$. Next, using the equation 2 modified to take into account the average thermal power available in the calciner $\left(\bar{q}^{\text {calc }}\right)$ per square meter of heliostat field, it is possible to have an estimate value for the heliostat aperture area $\left(A^{C S P}\right)$ :

$$
\bar{Q}^{\text {Calc }}=A^{C S P} \cdot \bar{q}^{\text {Calc }}=47,000 k W
$$

where

$$
\bar{q}^{\text {Calc }}=\frac{\sum_{1}^{8760} \eta_{i}^{\text {opt }} \cdot \eta^{\text {receiver }} \cdot D N I_{i}}{8760} \approx 0.1089 \frac{\mathrm{kW}}{\mathrm{m}^{2}}
$$

By using SAM [20] for the simulation of solar tower plant located in Seville, the average thermal power in the re- 
Table 2: References for estimating CaL components $\left(r_{\text {exch }}=1.18\right.$ [33]: average exchange rate EUR USD, 2018)

\begin{tabular}{llll}
\hline Component & Scaling parameter & Investment cost $(\mathrm{IC})$ in MUSD & Ref. \\
\hline Calciner & Thermal Power $\left(M W_{t h}\right)$ & $\mathrm{IC}=\left(13140 \cdot Q_{\text {calc }}^{0.67} \cdot 10^{-6}\right) \cdot r_{\text {exch }}$ & {$[34]$} \\
Carbonator & Thermal Power $\left(M W_{t h}\right)$ & $\mathrm{IC}=\left(16591 \cdot Q_{\text {carb }}^{0.67} \cdot 10^{-6}\right) \cdot r_{\text {exch }}$ & {$[34]$} \\
Steam power cycle & Cycle gross capacity $\left(M W_{e}\right)$ & $\mathrm{IC}=(290+1040) \cdot P_{\text {max }} \cdot 10^{-6}$ & {$[20]$} \\
Heat exchangers & area $\left(m^{2}\right)$ and pressure $(b a r)$ & $\mathrm{IC}=\left(2546.9 \cdot A_{H E}^{0.67} \cdot P_{H E}^{0.28} \cdot 10^{-6}\right) \cdot r_{e x c h}$ & {$[34]$} \\
Cooling towers & Thermal Power $\left(M W_{t h}\right)$ & $\mathrm{IC}=\left(32.3 \cdot Q_{\text {cool }} \cdot 10^{-3}\right) \cdot r_{\text {exch }}$ & {$[34]$} \\
$\mathrm{CO}_{2}$ compressors and turbines & - & See reference for calculation procedure & {$[34]$} \\
$\mathrm{CO}_{2}$ storage vessel & - & See reference for calculation procedure & {$[35]$} \\
Solids storage tanks & - & See references for calculation procedure & {$[36],[35]$} \\
\hline
\end{tabular}

Table 3: Validation Aspen Plus ${ }^{T M}$

\begin{tabular}{ll|cc|cc|cc|} 
& & \multicolumn{2}{|c|}{$100 M W_{t h}, \mathrm{SM}=3$} & \multicolumn{3}{|c|}{$33 M W_{t h}, \mathrm{SM}=1$} & \multicolumn{2}{c}{$100 M W_{t h}, \mathrm{x}=0.3$} \\
item & unit & Aspen & Python & Aspen & Python & Aspen & Python \\
\hline $\mathrm{s} 2$ & $\mathrm{~kg} / \mathrm{s}$ & 216.6 & 215.8 & 72.2 & 71.6 & 125.6 & 125.2 \\
$\mathrm{c} 2$ & $\mathrm{~kg} / \mathrm{s}$ & 64.6 & 64.3 & 64.6 & 64 & 33.9 & 33.8 \\
$\mathrm{~g} 9$ & $\mathrm{~kg} / \mathrm{s}$ & 133.9 & 134 & 133.8 & 134.4 & 132.6 & 132.7 \\
$\mathrm{~g} 13$ & $\mathrm{~kg} / \mathrm{s}$ & 126.2 & 126.5 & 126.2 & 126.8 & 124.6 & 124.7 \\
$\mathrm{ST}$ & $M W$ & 5.8 & 5.8 & 1.9 & 1.9 & 6.1 & 6.1 \\
$\mathrm{MC}$ & $M W$ & 12.9 & 12.8 & 12.9 & 11.5 & 12.8 & 12.7 \\
$\mathrm{MT}$ & $M W$ & 23.9 & 24 & 23.9 & 24 & 23.6 & 23.6 \\
$\mathrm{HPSC}$ & $M W$ & 5.3 & 5.3 & 0 & 0 & 5.6 & 5.6 \\
$\mathrm{HPST}$ & $M W$ & 0 & 0 & 0 & 0 & 0 & 0 \\
$\mathrm{HXG}$ & $M W$ & 75.9 & 75.8 & 75.9 & 76 & 75 & 74.8 \\
$P^{N e t}$ & $M W$ & 8.2 & 8.4 & 11.3 & 12.7 & 9.3 & 9.5 \\
\hline
\end{tabular}

Table 4: Scalarisation method

\begin{tabular}{ll|c|c|c|} 
Objective & unit & $\omega=0$ & $\boldsymbol{\omega}=\mathbf{1}$ & $\omega \rightarrow \infty$ \\
\hline$E^{\text {net } *}$ & GWh year $^{-1}$ & 118.2 & $\mathbf{1 1 7 . 6}$ & 115.6 \\
LPSC & GWh year $^{-1}$ & 24.6 & $\mathbf{2 1 . 0}$ & 18.9 \\
\hline
\end{tabular}

ceiver per square meter of heliostat reflective area is approximately $0.1032 \mathrm{~kW} / \mathrm{m}^{2}$. Hence,

$$
A^{C S P} \approx 430,000 \mathrm{~m}^{2}
$$

Then, with this solar field aperture area, the design capacity of the calciner is calculated considering the equation given above (with $\bar{\eta}^{\text {opt }} \approx 0.53, \eta^{\text {receiver }}=0.85, D N I_{\text {design }}=$ 0.95):

$$
Q^{\text {calc,design }} \approx 180 M W_{t h}
$$

After that, in order to find the capacities of each component mentioned in section 3.4, this thermal power is used as input in the Aspen model $\left(Q^{\text {calc }}=180 M W_{t h}\right)$, and the following capacities for each components were obtained:

$$
\begin{aligned}
P^{\mathrm{ST}} & \approx 10 \mathrm{MW} \\
P^{\mathrm{MC}} & \approx 23 \mathrm{MW} \\
P^{\mathrm{MT}} & \approx 43 \mathrm{MW} \\
P^{\mathrm{HPSC}} & \approx 10 \mathrm{MW} \\
P^{\mathrm{HPST}} & \approx 2 \mathrm{MW}
\end{aligned}
$$

Then, a number of storage hours can be defined to combine with the specific power production defined above, to estimate the capacity of the $\mathrm{CaO}$ storage tank (with $\rho_{\mathrm{CaO}} \approx 3370 \mathrm{~kg} / \mathrm{m}^{3}$ [38], and values of porosity and packing density of solids equals to 0.5 and 0.6 respectively). For instance, with 20 hours of storage:

$$
\begin{aligned}
\xi_{i, P} & =0.053 \frac{M W h}{\operatorname{ton}_{C a O}}=\frac{15 \mathrm{MW} \cdot 20 \mathrm{~h}}{S T O^{C a O} \cdot \rho_{C a O}} \\
\rightarrow S T O^{C a O} & \approx 5650 \mathrm{~m}^{3}
\end{aligned}
$$

Now, considering the following properties in the storage tanks: $\rho_{\mathrm{CaCO}_{3}} \approx 2700 \mathrm{~kg} / \mathrm{m}^{3}[38]$ (porosity $=0.5$ ) and $\rho_{\mathrm{CO}_{2}} \approx 762 \mathrm{~kg} / \mathrm{m}^{3}$, a $\mathrm{CaO}$ conversion $\mathrm{X}=0.15$, an estimate of the capacity in $\mathrm{m}^{3}$ of the two other tanks can be calculated as a ratio of $S T O^{C a O}$, where $V_{m, i}$ is the molar volume of substance $i$, defined as the volume occupied by 
one mole of component $\mathrm{i}$ in the storage tank or vessel, by the following relationships:

$$
\begin{aligned}
V_{m, i} & =\frac{M W_{i}}{\rho_{i}} \\
S T O^{S o l i d s} & =S T O^{\mathrm{CaO}} \cdot\left(x \cdot \frac{V_{m, C a C O_{3}}}{V_{m, C a O}}+(1-x)\right) \\
& \approx 5735 \mathrm{~m}^{3} \\
S T O^{C O_{2}} & =S T O^{\mathrm{CaO}} \cdot\left(x \cdot \frac{V_{m, C O_{2}}}{V_{m, C a O}}\right) \approx 875 \mathrm{~m}^{3}
\end{aligned}
$$

Finally, according to section 2.5, the model was evaluated with $\omega=0$ to maximise the energy dispatched and the capacities of all components indicated above. By the operational optimisation routine, it was calculated that the total net energy delivered in one year is $118.4 \mathrm{GWh}$, and the average power dispatched is $13.5 \mathrm{MW}$. Therefore, for the following calculations, the power commitment will be defined as $P_{i}^{\text {commit }}=13.5 M W, \forall i$.

\section{Results and Analysis}

To compare the results of different designs, nine configurations were analysed, which are summarised in table 5. The estimated capacities above are shown as "Base Case" configuration. The columns of table 5 show the name given to the configuration (Base Case, A to $\mathrm{H}$ ), then the aperture area of the heliostat field, the power capacity of the steam turbine, the main compressor and turbine capacities, next, the capacities of the high pressure compressor and turbine, columns 8 to 10 show the capacities of the storage tanks, and finally, the photovoltaic solar field area. In each row, different designs are presented, which are related to the Base Case, and all the configurations have the same aperture area of the heliostat field. For example, in configuration A the capacity of each component was increased by $20 \%$, while in configuration B by $50 \%$. Compressors and turbines of configuration $\mathrm{C}$ increased by $50 \%$ and storage remains the same. Capacities of the storage systems in configuration D were multiplied by 3. Configuration E, F, $\mathrm{G}$ and $\mathrm{H}$ are similar to $\mathrm{B}(50 \%$ increase in the capacity of each component), but now integrated with 10, 20, 30 and 40 hectare $\left(1\right.$ hectare $\left.=10,000 \mathrm{~m}^{2}\right)$ of photovoltaic solar field area.

The results of the operational optimisation for all configurations described in table 5 are presented in table 6 . This table shows all configurations and all key performance indicators mentioned in section 2.3.

First, the Base Case: according to table 6, for this configuration and considering the typical meteorological year, the total net energy delivered to the network reaches 117.6 GWh (97.2 GWh dispatched to the commitment and 20.4 GWh surplus sent to the grid), and $17.8 \%$ of the commitment is not supplied. $52.1 \mathrm{GWh}_{t h}$ have to be curtailed in the solar field, and the difference between the initial and the final hour of operation was $220 \mathrm{MWh}$ (equivalent to approximately 16 hours fulfiling the $13.5 \mathrm{MW}$ commitment). The average net power was 13.4 MW, while the maximum power dispatched by the system was $22 \mathrm{MW}$. The capacity factor is close to $65.2 \%$, and it is highly dependent on the capacity of the main components. As a comparison, a capacity factor of $58 \%$ was estimated by [25] for a CSP with 16 hours of TCES. In a future work, the capacity factor of this hybrid solar power plant would be improved by the optimisation of the size of the units. The efficiency based on the energy used in the receiver is $32.8 \%$ (compared with 32.1 estimated by [17]), and the efficiency based on direct normal irradiation falls to $12.2 \%$. Finally, the estimated investment is 323 MUSD and the operational and maintenance costs are 1.9 MUSD per year, resulting in a levelised cost of energy of $251.8 \mathrm{USD} \mathrm{MWh}^{-1}$.

Comparing the Base Case with configuration A, the results indicate that by increasing the capacities of all components by $20 \%$, the net energy increases in $11 \%$ and the curtailment is reduced by $76 \%$, improving the global efficiency based on the DNI. The LPSP still exceeds $15 \%$, and although the investment increase by $2 \%$, the LCOE is reduced by $7 \%$. Then, configuration B (which increases all capacities by $50 \%$ ), resulted in zero curtailment, which means that in this configuration, the design of the CSP$\mathrm{CaL}$ is oversized. The previous results show the key importance of selecting a certain equipment size for the plant efficiency, which is out of the scope of the present paper, but it will be the bases for a future optimisation study.

When comparing configurations B, C and D, it is possible to note that, starting with the Base Case, an increase in the capacity of compressors and turbines results in more energy dispatched but a lower dispatchability and capacity factor compared with increasing the storage tank capacities, nevertheless, a better approximation to an optimal design would be by an appropriate and independent sizing of all units. Therefore, this enhances the importance of including a second optimisation stage in order to find the best design based on technical and financial performances. Finally, configurations E, F, G and H show that the integration of a photovoltaic system is important to reduce the levelised cost of the energy, by including intermittent (non-dispatchable) but less expensive power generation. In these cases, the LCOE becomes less than 200 USD $\mathrm{MWh}^{-1}$. However, the integration of PV without a reduction in the capacities of the CSP-CaL system means a large energy generation and a large surplus that have to be dispatched to the network. For instance, in configuration $\mathrm{G}$, which includes 30 hectare of $\mathrm{PV}$ modules, the energy dispatched to fulfil the commitment is $111.1 \mathrm{GWh}(47 \%$ of total) while the excess of energy that have to be sent to the grid reaches $124.4 \mathrm{GWh}$ (53\% of total). In this case, it is possible that the dispatch of the surplus has negative effects on the local market, and that, depending on the mechanisms of the market, the energy may not be sold at a competitive price.

In order to know the power generation profiles of a hy- 
brid solar power plant with thermochemical energy storage, figures $2 \mathrm{a}$ and $2 \mathrm{~b}$ show two weeks of operation of configuration $\mathrm{G}$, one week in summer and another in winter along with the solar resource. The continuous purple line and the dashed black line show the solar irradiation (direct normal and global tilted respectively), for the location under study. The green and orange bars of the diagrams represent the power dispatched by the PV system and the CSP-CaL respectively. These results highlight that in the case of a hybrid solar power plant composed of CSP-CaL and PV, the strategy suggested by the optimisation routine is that the photovoltaic system delivers energy during the day, while the CSP-CaL stores energy to be dispatched during the night, unless there is a large solar irradiation available that allows the CSP-CaL to dispatch energy during day and night (in the case of summer). In addition, these results demonstrate the importance of the multi-objective optimisation technique presented. The diagram confirms that during winter and cloudy summer days, the CSP-CaL dispatch energy following both objectives, maximising the energy delivered, and fulfiling the commitment. Another crucial finding, shown in the diagram as a dashed red line, is the state of charge of the $\mathrm{CaO}$ storage tank. Because the state of charge of the storage never reaches $0 \%$ during the week presented for the summer, and despite that there is no restriction in the maximum capacity that can be dispatched, could be inferred that the storage system is oversized compared with the capacities of the generation units (compressor, turbines). Besides, the operation profile during winter suggests that there are some capacities that could be increased in the CSP-CaL system in order to increase the dispatchability of the hybrid plant.

\subsection{Sensitivity Analysis}

In this last section, a sensitivity analysis will be carried out by varying different financial and technical parameters, as well as the design of some of the components of configuration $\mathrm{G}$ presented in table 6 . The parameters selected for the sensitivity analysis and its original values are:

$$
\begin{aligned}
\eta^{\text {receiver }} & =0.85, \text { efficiency reveiver-calciner } \\
r & =7 \%, \text { annual interest rate } \\
A^{P V} & =30,000 \mathrm{~m}^{2}, \text { area photovoltaic field } \\
\kappa^{S t o} & =1, \text { multiplier capacities storage tanks } \\
\kappa^{T \& C} & =1, \text { multiplier capacities turbines and compressors }
\end{aligned}
$$

$\zeta^{\text {Reactors }}=1$, multiplier investment carbonator and calciner

In this case, because the analysis covers financial and technical parameters, appropriate key performance indicators are the levelised cost of the energy (LCOE) and the loss of power supply probability (LPSP) (see section 2.3). Figures $3 \mathrm{a}$ and $3 \mathrm{~b}$ show the sensitivity analysis for the LCOE and LPSP by varying the parameters described above between minus $10 \%$ and plus $10 \%$ from the original value reported.
Figure 3a indicates that the parameters that have the largest influence on the LCOE are the efficiency of the calciner, the interest rate, and the investment cost of reactors. The efficiency of the calciner increases the thermal energy available in the endothermic reaction and the total energy dispatched, for instance, if $\eta^{\text {receiver }}$ is increased by $5 \%\left(\eta^{\text {receiver }} \approx 0.89\right)$, the LCOE decreases by $3 \%$. Moreover, the configuration of the cycle could integrate different components to increase the cycle efficiency as shown in [39], in order to improve the affordability and dispatchability of the system. Next, the interest rate also has an important influence in the estimation of the LCOE, for example, if the project can be financed with a $r \approx 6.3 \%$ (instead of $7 \%$ ), the LCOE falls by $6 \%$. Finally, a reduction in $10 \%$ in the capital cost of the reactors (calciner and carbonator) decreases the LCOE in 4\%. This reduction is very likely to be achieved because this technology is at an early stage of maturity. Furthermore, the LCOE is highly dependent on the location of the power plant. In a future study, different regions will be analysed in order to compare key performance indicators under different solar resource and market features. For instance, if configuration $\mathrm{G}$ (with modifications in the solar field to keep fixed the total energy available) is analysed under the solar irradiation data corresponding to Atacama-1, a hybrid solar power plant located in Northern Chile [24], the LCOE drops to 137.8 USD $M W h^{-1}$ and the LPSP reaches $0.1 \%$. For the LPSP, by increasing any of the parameters shown in figure $3 \mathrm{~b}$, the energy dispatched to fulfil the commitment increases (and the LPSP decreases). Figure $3 b$ shows that increasing the efficiency of the calciner or the capacity of the storage is key to increase the dispatchability. Finally, when it focuses on increasing the component sizes, the results and diagrams suggest that by increasing the storage capacities is possible to dispatch a similar amount of energy, and when a large storage capacity is available, it is possible to manage the time when energy is dispatched, increasing the dispatchability of the power plant, allowing a long-term energy storage capacity.

\section{Conclusions}

This paper presents a multi-objective optimisation framework and a linearised model for the operation of a concentrating solar power plant with calcium-looping $(\mathrm{CaL})$ as thermochemical energy storage, through the implementation of a linear scalarisation technique. Different designs and the hybridisation with a photovoltaic system were evaluated. This contribution provides relevant information to make renewable energy systems affordable and reliable. The optimisation framework focuses on finding the best strategy of a hybrid power plant to dispatch energy during the year, and is able to report the hourly power generation and consumption profiles by each main component of the power plant, as well as the mass flow rates of each stream. 


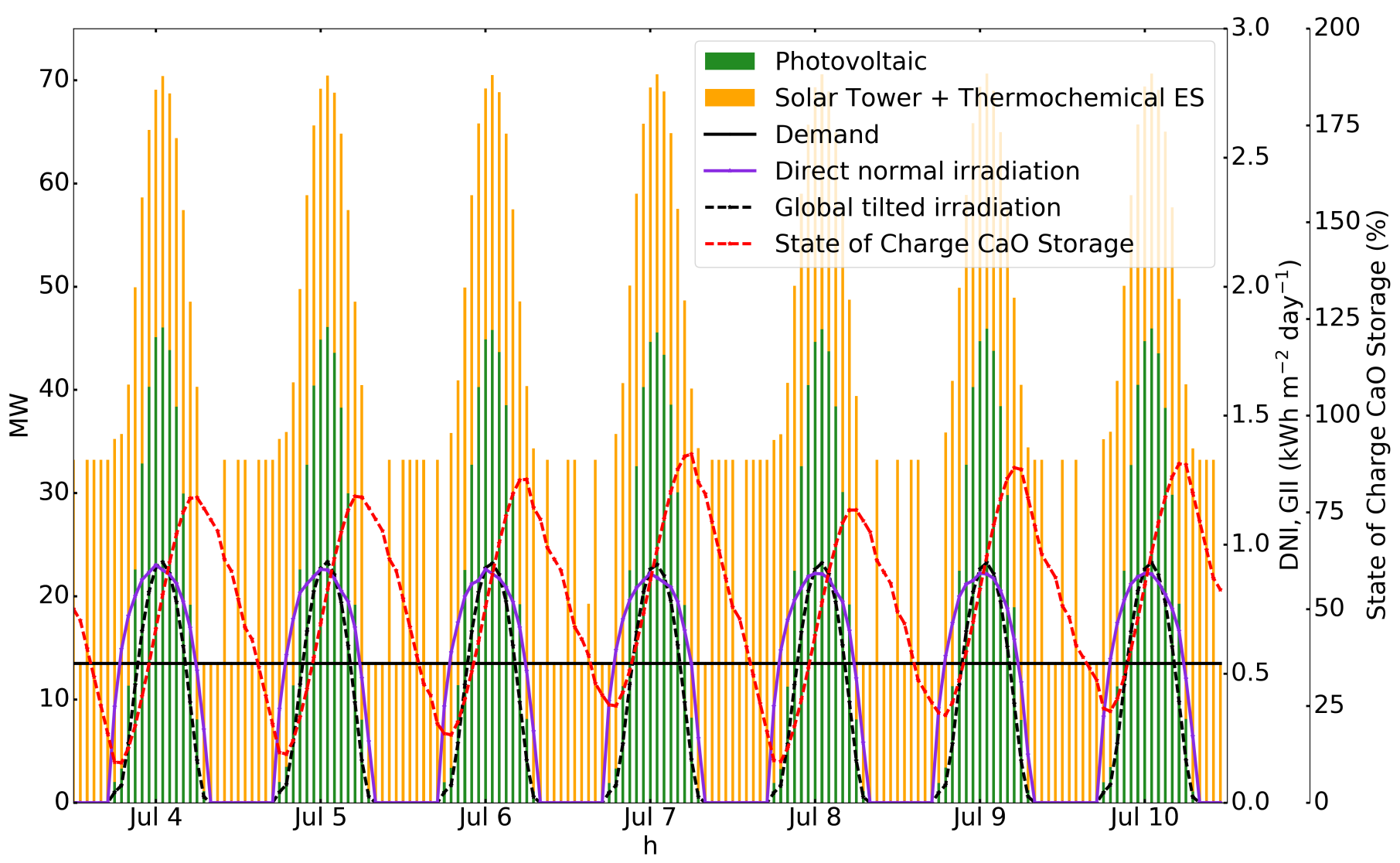

(a) Summer, 1 week

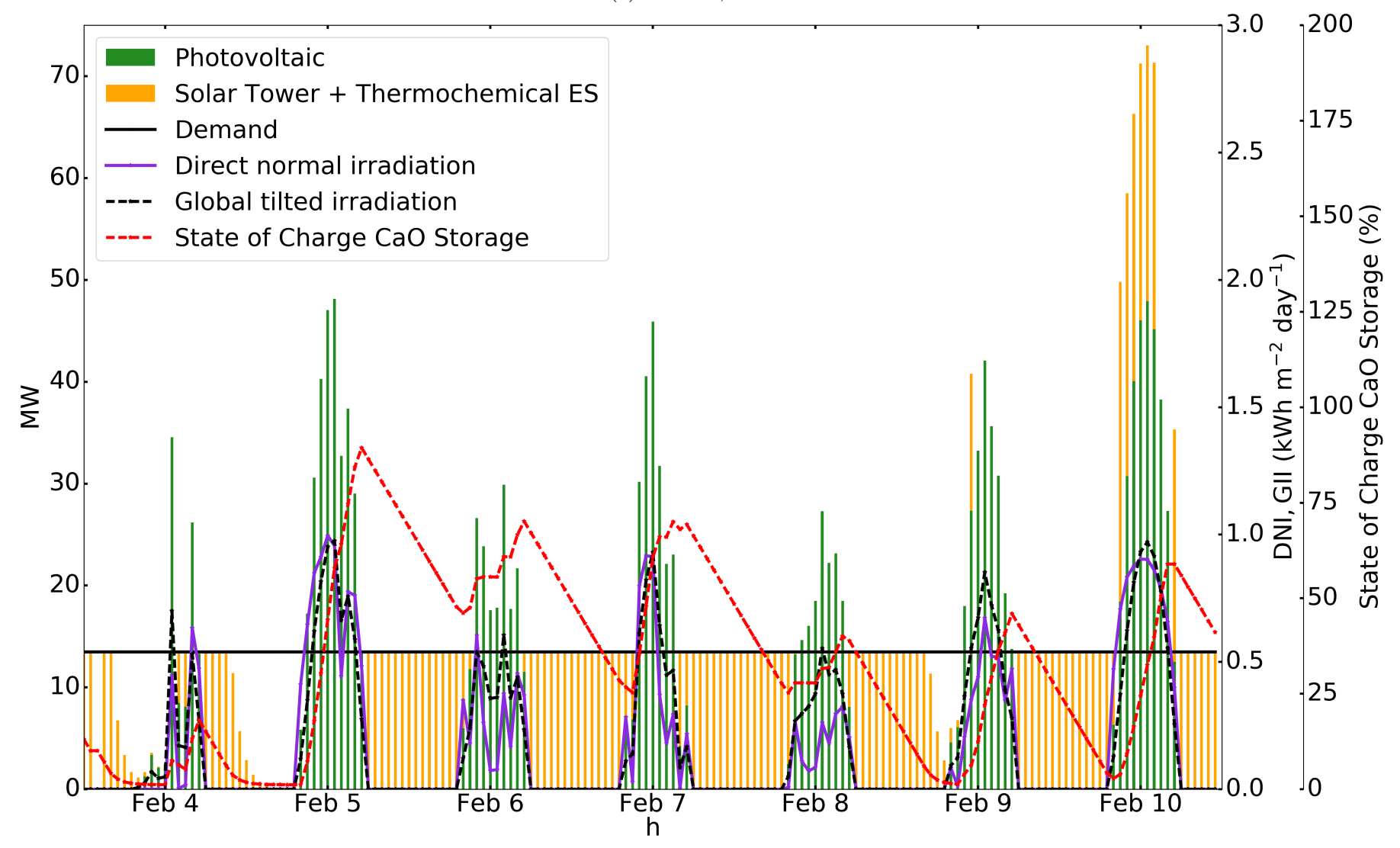

(b) Winter, 1 week

Figure 2: Optimised Operation of the hybrid solar power plant, configuration G, plus solar resource and commitment 
Table 5: Different configurations analysed

\begin{tabular}{|c|c|c|c|c|c|c|c|c|c|c|}
\hline $\begin{array}{l}\text { Configuration } \\
\text { name }\end{array}$ & $\begin{array}{c}A^{C S P} \\
m^{2}\end{array}$ & $\begin{array}{l}P^{\mathrm{ST}} \\
\mathrm{MW}\end{array}$ & $\begin{array}{l}P^{\mathrm{MC}} \\
\mathrm{MW}\end{array}$ & $\begin{array}{l}P^{\mathrm{MT}} \\
\mathrm{MW}\end{array}$ & $\begin{array}{c}P^{\mathrm{HPSC}} \\
\mathrm{MW}\end{array}$ & $\begin{array}{c}P^{\mathrm{HPST}} \\
\mathrm{MW}\end{array}$ & $\begin{array}{c}\mathrm{STO}^{\mathrm{CO}_{2}} \\
\mathrm{~m}^{3}\end{array}$ & $\begin{array}{c}S T O^{C a O} \\
m^{3}\end{array}$ & $\begin{array}{c}\text { STO } \\
m^{\text {Solids }}\end{array}$ & $\begin{array}{c}A^{\mathrm{PV}} \\
m^{2}\end{array}$ \\
\hline Base Case & 430,000 & 10 & 23 & 43 & 10 & 2 & 5650 & 5735 & 875 & 0 \\
\hline A & 430,000 & 12 & 28 & 52 & 12 & 2.5 & 6780 & 6880 & 1050 & 0 \\
\hline B & 430,000 & 15 & 35 & 65 & 15 & 3 & 8475 & 8600 & 1310 & 0 \\
\hline $\mathrm{C}$ & 430,000 & 15 & 35 & 65 & 15 & 3 & 5650 & 5735 & 875 & 0 \\
\hline $\mathrm{D}$ & 430,000 & 10 & 23 & 43 & 10 & 2 & 16950 & 17200 & 2625 & 0 \\
\hline $\mathrm{E}$ & 430,000 & 15 & 35 & 65 & 15 & 3 & 8475 & 8600 & 1310 & 100,000 \\
\hline $\mathrm{F}$ & 430,000 & 15 & 35 & 65 & 15 & 3 & 8475 & 8600 & 1310 & 200,000 \\
\hline$G$ & 430,000 & 15 & 35 & 65 & 15 & 3 & 8475 & 8600 & 1310 & 300,000 \\
\hline $\mathrm{H}$ & 430,000 & 15 & 35 & 65 & 15 & 3 & 8475 & 8600 & 1310 & 400,000 \\
\hline
\end{tabular}

Table 6: Operational optimisation all previous designs (table 5)

\begin{tabular}{|c|c|c|c|c|c|c|c|c|c|c|}
\hline KPI & unit & Base Case & A & B & $\mathrm{C}$ & $\mathrm{D}$ & $\mathrm{E}$ & $\mathrm{F}$ & G & $\mathrm{H}$ \\
\hline$E^{\text {net* }}$ & GWh year $^{-1}$ & 117.6 & 131.1 & 136.6 & 134.2 & 123.5 & 169 & 202 & 235.1 & 268.2 \\
\hline$L P S P$ & $\%$ & 17.8 & 15.9 & 14.43 & 17.4 & 12.9 & 9.2 & 7.1 & 6.1 & 5.3 \\
\hline$E^{\text {commit }}$ & GWh year $^{-1}$ & 97.2 & 99.5 & 101.2 & 97.7 & 103.0 & 107.4 & 109.8 & 111.1 & 111.9 \\
\hline$E^{e x c e s s}$ & GWh year $^{-1}$ & 20.4 & 31.6 & 35.4 & 36.5 & 20.5 & 61.6 & 92.2 & 124.4 & 156.2 \\
\hline$E^{\text {curtailed }}$ & $G W h_{\text {th }}$ year $^{-1}$ & 52.1 & 12.5 & 0 & 8.8 & 32.5 & 0 & 0 & 0 & 0 \\
\hline$\Delta E_{f-i}$ & MWh & 220 & 330 & 420 & 270 & 820 & 420 & 420 & 420 & 420 \\
\hline $\bar{P}^{n e t}$ & MW & 13.4 & 15.0 & 15.6 & 15.3 & 14.1 & 19.3 & 23.1 & 26.8 & 30.6 \\
\hline$P_{C S P}^{\max }$ & MW & 22.0 & 26.6 & 33.2 & 33.2 & 22.0 & 33.2 & 33.2 & 33.2 & 33.2 \\
\hline$C F_{C S P}$ & $\%$ & 65.2 & 59.9 & 49.5 & 48.3 & 69.1 & 49.5 & 49.5 & 49.5 & 49.5 \\
\hline$\eta_{C S P, R e c}$ & $\%$ & 32.8 & 33.0 & 33.3 & 33.4 & 32.7 & 33.1 & 33.1 & 33.2 & 33.2 \\
\hline$\eta_{C S P, D N I}$ & $\%$ & 12.2 & 13.6 & 14.2 & 13.9 & 12.8 & 14.1 & 14.1 & 14.1 & 14.1 \\
\hline$P_{\text {hybrid }}^{\max }$ & MW & 22.0 & 26.6 & 33.2 & 33.2 & 22.0 & 44.8 & 58.9 & 74.9 & 91.3 \\
\hline Investment & MUSD & 323 & 331 & 341 & 336 & 341 & 384 & 427 & 470 & 513.1 \\
\hline O\&M & MUSD year ${ }^{-1}$ & 1.9 & 2.2 & 2.7 & 2.7 & 1.9 & 2.8 & 3.0 & 3.1 & 3.3 \\
\hline$L C O E$ & $\mathrm{USD}_{\mathrm{MWh}}{ }^{-1}$ & 251.8 & 233.3 & 233.8 & 234.8 & 252.4 & 211.7 & 196.2 & 184.9 & 176.4 \\
\hline
\end{tabular}

The results summarise key performance indicators obtained by optimising the operation of a power plant located in Seville, Spain, using the solar irradiation data of the typical meteorological year as input. Among these indicators it is possible to find the total energy dispatched during the year, the mismatch between supply and demand for a given commitment, the overall efficiency of the power plant, the investment and the levelised cost of the energy. In addition, by changing the input data it is possible to optimise a similar solar power plant in any location.

The findings of this study indicate that the use of a thermochemical energy storage system in concentrated solar power plants increases the dispatchability, and by hybridising with a photovoltaic system, it can become cost competitive. However, the high differences in the solar irradiation in Seville between summer and winter could have a negative effect on the power system during summer by dispatching a large amount of power during the day. Therefore, a detailed analysis of the local electrical system and its flexibility have to be analysed together with the correct design of the power plant.

Our research has highlighted the importance of the multi- objective optimisation of the operation of a renewable power plant to reduce the fluctuations and maximise the energy delivered, which also influences the levelised cost of the energy. When the design of the main components of the CaL is oversized (keeping the solar field fixed), less energy have to be curtailed, and more energy can be dispatched. However, this requires larger investments and results in lower capacity factors, therefore a proper balance between capacities and curtailed energy should be pursued. In addition, it was found that the integration of a large CaL system, which has the capacity to store a larger amount of energy, results in an significant reduction in the loss of power supply and an increase in the capacity factor. This means that a system with a large capacity to store energy can work as a medium (or even long) term energy storage. Similar to the previous point, greater energy storage capacity requires larger investment.

The hybridisation with a photovoltaic system has important effects. Because a larger solar field area is available, there is an improvement in both the energy dispatched and the loss of power supply. In addition, the operational strategy allows that, during the day the PV dispatches 


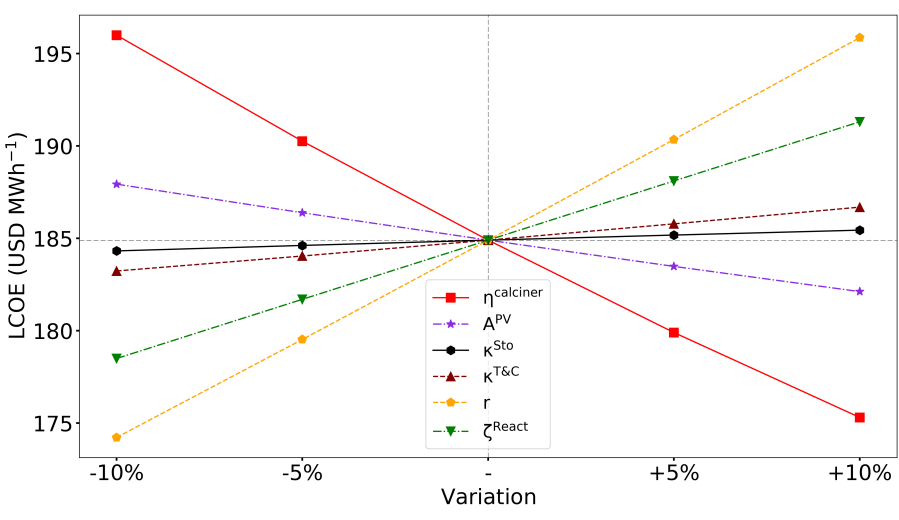

(a) Levelised cost of electricity

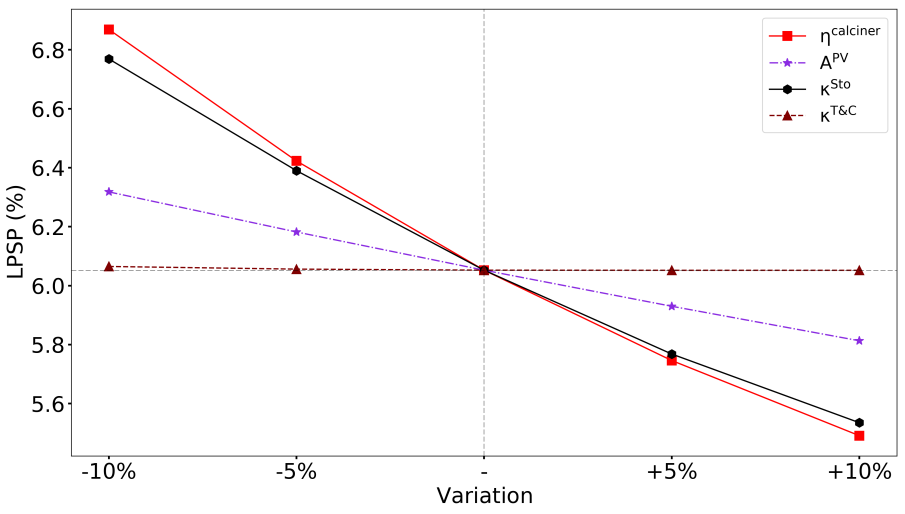

(b) Loss of power supply probability

Figure 3: Sensitivity analysis

power while the CSP stores energy, and during the night the CSP could dispatch, reducing the mismatch between supply and demand when no solar irradiation is available. Because PV is cheaper compared with CSP, the hybridisation results in a global reduction in the levelised cost of energy.

This study is the first step to improve the modelling and optimisation of the integration of $\mathrm{CaL}$ as thermochemical energy storage system in hybrid solar power plants. Currently a second stage optimisation is under development, in order to define the best capacities of the main components of the power plant by exploiting synergies related with the dispatchability of CSP-CaL and affordability of PV systems.

\section{Acknowledgments}

Ruben Bravo is supported by a PhD Scholarship from Becas Chile, National Commission for Scientific and Technological Research (CONICYT-Chile), Folio 72160177. The present research was supported by the Energy Technology Partnership (ETP), International Exchange Grants for Postgraduate and Early Career Researcher Exchanges (PECRE) 2018. Part of this project was developed within the Horizon 2020 Project Socratces, Grant Agreement 727348.

\section{References}

[1] IEA, Energy Technology Perspectives 2017, International Energy Agency, Organisationf for Economic Co-operation and Development (2017). doi:10.1787/energy_tech-2017-en.

[2] NREL, System Advisor Model (SAM) (2018). URL https://sam.nrel.gov/

[3] M. Pehl, A. Arvesen, F. Humpenöder, A. Popp, E. G. Hertwich, G. Luderer, Understanding future emissions from low-carbon power systems by integration of life-cycle assessment and integrated energy modelling, Nature Energy 2 (12) (2017) 939-945. doi : 10.1038/s41560-017-0032-9.

[4] M. Keay, D. Robinson, The limits of auctions: reflections on the role of central purchaser auctions for long-term commitments in electricity systems, Tech. rep. (2019). doi:10.26889/ 9781784671341.

[5] P. Denholm, M. Hand, Grid flexibility and storage required to achieve very high penetration of variable renewable electricity, Energy Policy 39 (3) (2011) 1817-1830. doi:10.1016/j.enpol. 2011.01.019.

[6] P. Denholm, J. Jorgenson, M. Miller, E. Zhou, C. Wang, Methods for Analyzing the Economic Value of Concentrating Solar Power with Thermal Energy Storage Methods for Analyzing the Economic Value of Concentrating Solar Power with Thermal Energy Storage, Tech. Rep. July, National Renewable Energy Laboratory (2015).

[7] R. Fernández, C. Ortiz, R. Chacartegui, J. M. Valverde, J. A. Becerra, Dispatchability of solar photovoltaics from thermochemical energy storage, Energy Conversion and Management 191 (2019) 237-246. doi:10.1016/j.enconman.2019.03.074.

[8] R. Bravo, D. Friedrich, Integration of energy storage with hybrid solar power plants, Energy Procedia 151 (2018) 182-186. doi: 10.1016/j.egypro.2018.09.045.

[9] C. Ortiz, R. Chacartegui, J. M. Valverde, A. Alovisio, J. A. Becerra, Power cycles integration in concentrated solar power plants with energy storage based on calcium looping, Energy Conversion and Management 149 (2017) 815-829. doi:10.1016/ j.enconman.2017.03.029.

[10] R. Bravo, D. Friedrich, Two-Stage, Multi-objective Optimisation Framework for an Efficient Pathway to Decarbonise the Power Sector, in: EngOpt 2018 Proceedings of the 6th International Conference on Engineering Optimization, Springer International Publishing, Cham, 2018, pp. 1420-1433. doi: 10.1007/978-3-319-97773-7_122.

[11] M. Medrano, A. Gil, I. Martorell, X. Potau, L. F. Cabeza, State of the art on high-temperature thermal energy storage for power generation. Part 2-Case studies, Renewable and Sustainable Energy Reviews 14 (1) (2010) 56-72. doi:10.1016/j.rser.2009. 07.036.

[12] B. Zalba, J. M. Marín, L. F. Cabeza, H. Mehling, Review on thermal energy storage with phase change: Materials, heat transfer analysis and applications, Applied Thermal Engineering 23 (3) (2003) 251-283. doi:10.1016/S1359-4311(02) 00192-8.

[13] P. Pardo, A. Deydier, Z. Anxionnaz-Minvielle, S. Rougé, M. Cabassud, P. Cognet, A review on high temperature thermochemical heat energy storage, Renewable and Sustainable Energy Reviews 32 (2014) 591-610. doi:10.1016/j.rser.2013. 12.014.

[14] R. Chacartegui, A. Alovisio, C. Ortiz, J. M. Valverde, V. Verda, J. A. Becerra, Thermochemical energy storage of concentrated solar power by integration of the calcium looping process and a CO 2 power cycle, Applied Energy 173 (2016) 589-605. doi: 10.1016/j . apenergy . 2016.04.053.

[15] R. L. Jaffe, T. Washington, The physics of energy, Cambridge University Press, Cambridge, United Kingdom ; New York, NY, 2018. doi : 10.1017/9781139061292.

[16] M. Petrollese, D. Cocco, Optimal design of a hybrid CSPPV plant for achieving the full dispatchability of solar energy power plants, Solar Energy 137 (2016) 477-489. doi: 10.1016/j.solener. 2016.08.027. 
[17] C. Ortiz, M. C. Romano, J. M. Valverde, M. Binotti, R. Chacartegui, Process integration of Calcium-Looping thermochemical energy storage system in concentrating solar power plants, Energy 155 (2018) 535-551. doi:10.1016/j.energy. 2018.04.180.

[18] A. Meier, N. Gremaud, A. Steinfeld, Economic evaluation of the industrial solar production of lime, Energy Conversion and Management 46 (6) (2005) 905-926. doi:10.1016/j.enconman. 2004.06 .005

[19] C. Ortiz, J. Valverde, R. Chacartegui, L. Perez-Maqueda, P. Giménez, The Calcium-Looping $(\mathrm{CaCO} 3 / \mathrm{CaO})$ process for thermochemical energy storage in Concentrating Solar Power plants, Renewable and Sustainable Energy Reviews 113 (2019) 109252. doi:10.1016/j.rser.2019.109252.

[20] NREL, Concentrating Solar Power Projects. URL https://www.nrel.gov/csp/solarpaces/

[21] R. H. Perry, D. W. Green, J. O. Maloney, Perry's Chemical engineers' handbook., seventh ed Edition, McGraw-Hill, New York ; London, 1997.

[22] I. Dincer, M. A. Rosen, P. Ahmadi, Optimization of energy systems, Wiley, 2017. doi:10.1002/9781118894484.

[23] E. Dick, Fundamentals of Turbomachines, Vol. 109, Springer, Dordrecht, 2015. doi:10.1007/978-94-017-9627-9.

[24] R. Bravo, D. Friedrich, Two-stage optimisation of hybrid solar power plants, Solar Energy 164 (2018) 187-199. doi:10.1016/ j.solener.2018.01.078.

[25] C. Ortiz, M. Binotti, M. C. Romano, J. M. Valverde, R. Chacartegui, Off-design model of concentrating solar power plant with thermochemical energy storage based on calciumlooping, in: AIP Conference Proceedings, Vol. 2126, AIP Publishing LLC, 2019. doi:10.1063/1.5117755.

[26] D. Y. Goswami, Principles of solar engineering, third edit Edition, Boca Raton, FL : CRC Press, 2015.

[27] Python Software Foundation, Python 3.5.3 (2017). URL https://www. python.org/

[28] W. E. Hart, C. D. Laird, J.-P. Watson, D. L. Woodruff, G. A. Hackebeil, B. L. Nicholson, J. D. Siirola, Pyomo - Optimization Modeling in Python, Vol. 67 of Springer Optimization and Its Applications, Springer International Publishing, Cham, 2017. doi:10.1007/978-3-319-58821-6.

[29] W. E. Hart, J. P. Watson, D. L. Woodruff, Pyomo: Modeling and solving mathematical programs in Python, Mathematical Programming Computation 3 (3) (2011) 219-260. doi:10.1007/ s12532-011-0026-8.

[30] L. Gurobi Optimization, Gurobi Optimizer Reference Manual (2019).

URL http://www.gurobi.com

[31] J. R. C. European Commission, JRC Photovoltaic Geographical Information System (PVGIS) - European Commission (2017). URL https://re.jrc.ec.europa.eu

[32] C. Ortiz, J. M. Valverde, R. Chacartegui, L. A. Perez-Maqueda, Carbonation of Limestone Derived $\mathrm{CaO}$ for Thermochemical Energy Storage: From Kinetics to Process Integration in Concentrating Solar Plants, ACS Sustainable Chemistry and Engineering 6 (5) (2018) 6404-6417. doi:10.1021/acssuschemeng. 8 b00199.

[33] J. Cherowbrier, • Euro to U.S. dollar exchange rate 1999-2018 - Statista (2019).

URL https://www.statista.com

[34] S. Michalski, D. P. Hanak, V. Manovic, Techno-economic feasibility assessment of calcium looping combustion using commercial technology appraisal tools, Journal of Cleaner Production 219 (2019) 540-551. doi:10.1016/j.jclepro.2019.02.049.

[35] A. Bayon, R. Bader, M. Jafarian, L. Fedunik-Hofman, Y. Sun, J. Hinkley, S. Miller, W. Lipiński, Techno-economic assessment of solid-gas thermochemical energy storage systems for solar thermal power applications, Energy 149 (2018) 473-484. doi: $10.1016 / j$. energy . 2017.11.084.

[36] M. Jonemann, Advanced Thermal Storage System with Novel Molten Salt: December 8, 2011 - April 30, 2013, Tech. rep. (2013). doi:10.2172/1080117.
[37] C. Ortiz, J. M. Valverde, R. Chacartegui, Energy Consumption for $\mathrm{CO} 2$ Capture by means of the Calcium Looping Process: A Comparative Analysis using Limestone, Dolomite, and Steel Slag, Energy Technology 4 (10) (2016) 1317-1327. doi: 10.1002/ente. 201600390 .

[38] J. M. Valverde, P. E. Sanchez-Jimenez, L. A. Perez-Maqueda, Limestone Calcination Nearby Equilibrium: Kinetics, $\mathrm{CaO}$ Crystal Structure, Sintering and Reactivity, The Journal of Physical Chemistry (2015). doi:10.1021/jp508745u.

[39] A. Alovisio, R. Chacartegui, C. Ortiz, J. M. Valverde, V. Verda, Optimizing the CSP-Calcium Looping integration for Thermochemical Energy Storage, Energy Conversion and Management 136 (2017) 85-98. doi:10.1016/j.enconman.2016.12.093. 